\title{
Association of prolapse of posterior cusp of mitral valve and atrial septal defect
}

\author{
Alastair McDonald, ${ }^{1}$ Alan Harris, Keith Jefferson, John Marshall, \\ and Lawson McDonald \\ From the Cardiac Departments of The London and St. George's Hospitals, \\ the National Heart Hospital, and the Institute of Cardiology, London
}

\begin{abstract}
Eleven patients with fossa ovalis atrial septal defects and prolapse of the posterior cusp of the mitral valve are described. Six patients had clinical evidence of mitral regurgitation, and in 2 others the electrocardiogram was unusual for uncomplicated fossa ovalis atrial septal defects. The varied appearance of the prolapsed cusp was shown by left ventricular angiography. The principal significance of this association is in its differentiation from atrioventricular defects.
\end{abstract}

The coincidence of prolapse of the posterior cusp of the mitral valve with fossa ovalis atrial septal defects has not previously been emphasized though the association occurred in 2 of 90 patients reported by Barlow et al. (I968) and 2 of 40 patients reported by Hancock and Cohn (1966). Prolapse of the posterior cusp of the mitral valve is now described in II patients who had, in addition, fossa ovalis atrial septal defects. A preliminary account of this work was given at a meeting of the British Cardiac Society in London in November 1969 (McDonald et al., 1970).

\section{Material and methods}

- The II patients were aged from 4 to 57 years; 3 were male and 8 female. Electrocardiograms, chest radiographs, and phonocardiograms were obtained in all patients and cardiac catheterization - and left ventricular angiography were performed. The findings at operation were available in 5 patients.

\section{Results}

- Symptoms Two patients were asymptomatic. Four had slight, and 4 moderate - exertional dyspnoea; supraventricular tachycardia caused paroxysmal palpitation in 3, and ventricular ectopic beats occurred in the other patient. A past history of rheumatic fever was

obtained in Case 6.

Received I October 1970.

- Address requests for reprints to Dr. Alastair McDonald, Cardiac Department, The London Hospital, Whitechapel, London E.1.
Signs Apart from the usual clinical findings of an atrial septal defect (Cleland et al., 1969), an abnormality of the mitral valve was suspected clinically in 6 patients (Table) who had a mitral pansystolic murmur which was associated with a mid-systolic click in 2 . In one patient (Case 8) who had moderate pulmonary valvar stenosis and subvalvar stenosis with reversal of the atrial shunt there was moderate central cyanosis and finger clubbing. The skeletal manifestations of Marfan's syndrome were present in Case 2.

Electrocardiography Eight patients had partial right bundle-branch block and 3 complete right bundle-branch block (Table). The mean frontal QRS axis showed right axis deviation (greater than $+90^{\circ}$ ) in 7 patients and was normal in 3. The frontal axis was unusual for uncomplicated fossa ovalis atrial septal defects in 2 patients. Abnormal left axis deviation $\left(>-30^{\circ}\right)$ was present in one case, and the axis was indeterminate in another, both having partial right bundlebranch block.

Radiology The findings in ro patients were typical of atrial septal defect with cardiac enlargement, dilatation of the pulmonary artery, and pulmonary plethora. There was absence of pulmonary plethora in one patient (Case 8) who had moderate pulmonary stenosis. In 2 patients (Cases 4 and 6) there was enlargement of the left atrium suggesting a mitral valvar lesion. 
TABLE Clinical findings and investigations in eleven patients

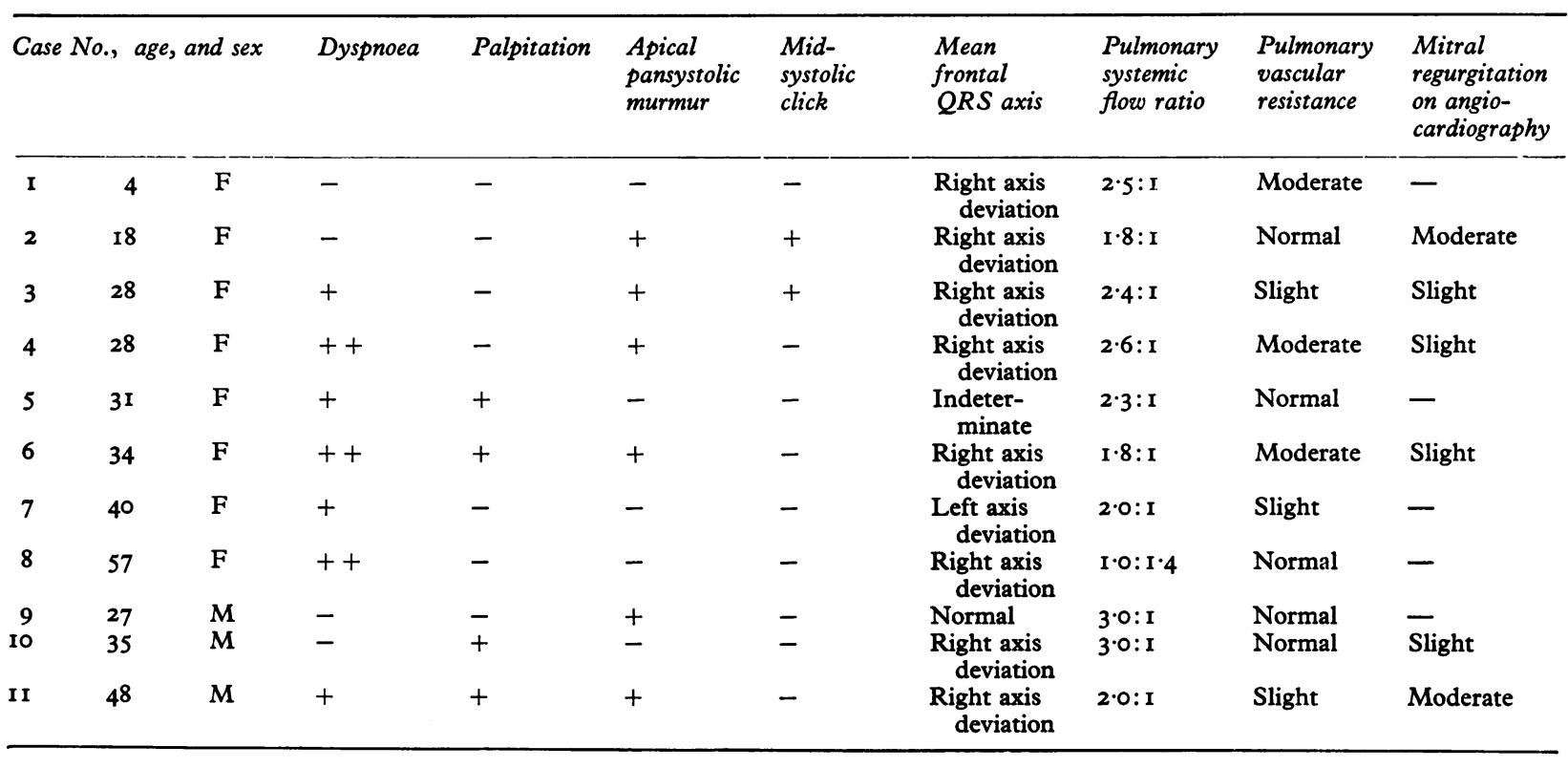

+ present, - absent.

Phonocardiography The records confirmed the auscultatory findings; an illustrative sound recording from Case 2 is shown in Fig. I.

Cardiac catheterization The presence of an atrial septal defect was shown in all patients. In Io patients the atrial shunt was from left to right, the pulmonary/systemic flow ratio varying from 3 to $I \cdot 7$ (Table). In the patient with pulmonary stenosis there was a

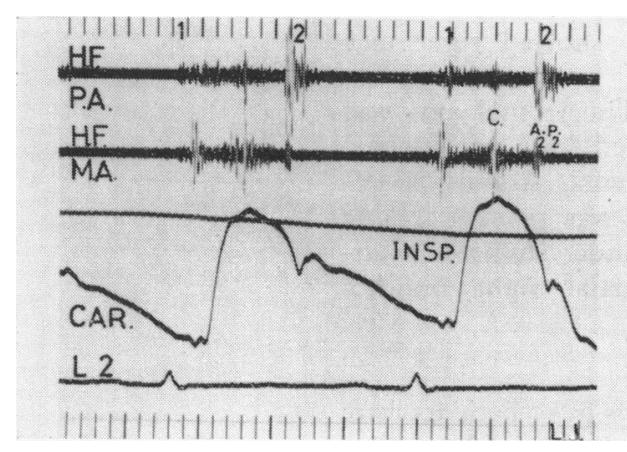

FIG. I Sound recording, Case 2. H.F., high frequency; P.A., pulmonary area; M.A., mitral area; CAR., external carotid pulse; L2, lead 2 of electrocardiogram; INSP., inspiration; $C$, systolic click; $A_{2}$, aortic component of second sound; $P_{2}$, pulmonary component of second sound. right-to-left shunt at atrial level resulting in moderate arterial desaturation. The pulmonary vascular resistance was normal in 7 patients and there was a slight to moderate rise in resistance in 5.

Angiography Left ventricular biplane angiograms (Elema-Schonander), or cineangiograms in the right anterior oblique were performed. Mitral regurgitation was seen in 6 patients; it was slight in 4 , and moderate in 2 (Table). Prolapse of the posterior cusp of the mitral valve was shown in all. The angiographic appearance of prolapse varied particularly with regard to the size and the direction of the prolapse. In the anteroposterior plane the prolapse appeared in some cases as a ballooning deformity at the right border of the left ventricle (Fig. 2), in others the prolapse occurred to either side of the mitral ring (Fig. 3). In a few the ballooning cusp was mainly directed posteriorly (Fig. 4) and was not well seen in the anteroposterior plane. The prolapse into the left atrium occurred in systole; in some cases a little medium was seen to be caught among folds of redundant cusp tissue, as the posterior cusp swung into the left ventricular cavity during diastole. The size of the prolapse was not related to the degree of mitral regurgitation. For example, in Case 5 (Fig. 4 and 5) a large prolapse was shown but the mitral valve remained fully competent. 


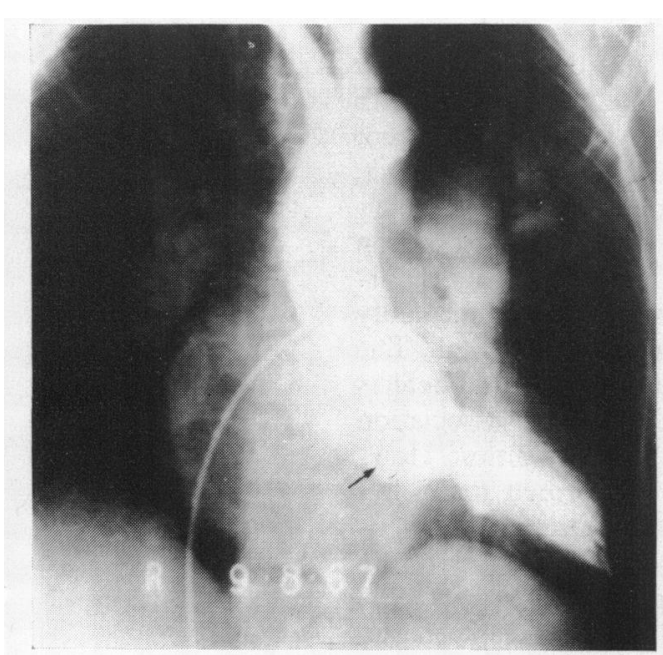

FIG. 2 Left ventricular angiogram, anteroposterior view, Case II. The arrow indicates the ballooning posterior cusp of the mitral valve outlined by contrast in the left atrium and left ventricle.

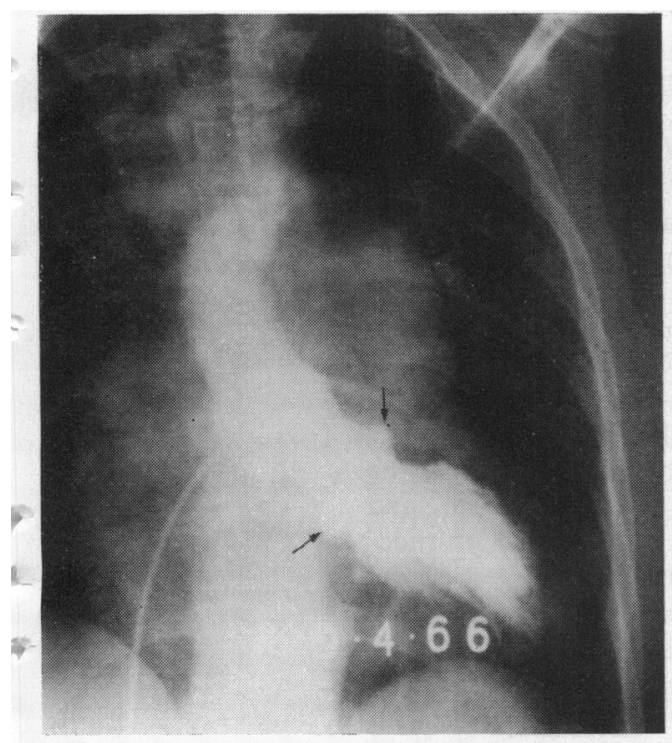

- FIG. 3 Left ventricular angiogram, antero-

posterior view, Case 7. The arrows indicate prolapse to either side of the mitral valve ring.

Surgery Surgery was undertaken in 5 patients and a fossa ovalis defect closed by direct suture. The appearances of the mitral valves * at operation varied. In one patient (Case 6) who had a past history of rheumatic fever 4 slight mitral stenosis was found and mitral valvotomy was performed, and no significant abnormality of the posterior cusp or chordae was noted. In 2 patients (Cases 3 and II) redundant posterior cusp tissue was found and in the latter patient (Case II), who had moderately severe mitral regurgitation, this was particularly noticeable and a posterior cusp valvuloplasty was performed. This procedure appeared to reduce the amount of regurgitation, yet after operation the mitral pansystolic murmur became a late systolic murmur. In the remaining 2 patients (Cases 4 and ro), in whom slight mitral regurgitation was shown, no significant abnormality was noted on viewing the mitral valve from the atrium. It may be impossible with a non-beating empty heart to show the dynamic abnormality of a prolapsing posterior cusp of the mitral valve, and this seems likely to apply to Cases 4,6 , and 10.

\section{Discussion}

Prolapse of the posterior cusp of the mitral valve was shown by left ventricular angiography in all II patients, but in only 6 patients had a mitral valve abnormality been clinically diagnosed by the presence of a mitral pansystolic murmur. In the other 5 patients there were no auscultatory features suggesting a mitral valvar lesion. An unusual mean frontal QRS in 2 of these patients was considered a possible indication that an atrioventricular defect might be present. The characteristic deformity of the left ventricular outflow tract in atrioventricular defects (Baron et al., 1964; Somerville and Jefferson, I968) was not found on angiography. In the remaining 3 patients the prolapse was an incidental finding at angiography. A late systolic murmur has been shown to be due to mitral regurgitation (Barlow et al., 1963; Segal and Likoff, 1964; Stannard et al., 1967) and left ventricular angiography has shown that the regurgitation is related to prolapse of the posterior cusp of the mitral valve (Barlow and Bosman, 1966; Criley et al., 1966). A mid or late systolic click is not uncommon and has been considered to be due to sudden chordal tension (Reid, 196I). The patients described here underline that prolapse of the posterior cusp need not occasion any abnormal physical signs, if mitral regurgitation is lacking, even when the size of the prolapse is considerable.

This type of deformity of the mitral valve has been noted in Marfan's syndrome (Read et al., 1964; Criley et al., 1966; Barlow et al., I968), and one patient in this series had the skeletal manifestations of Marfan's syndrome. In most instances, however, no definite aetiological factor is identified. Rheumatic endocarditis is not infrequently noted (Barlow et al., 1968), as in one case in this series, but it 


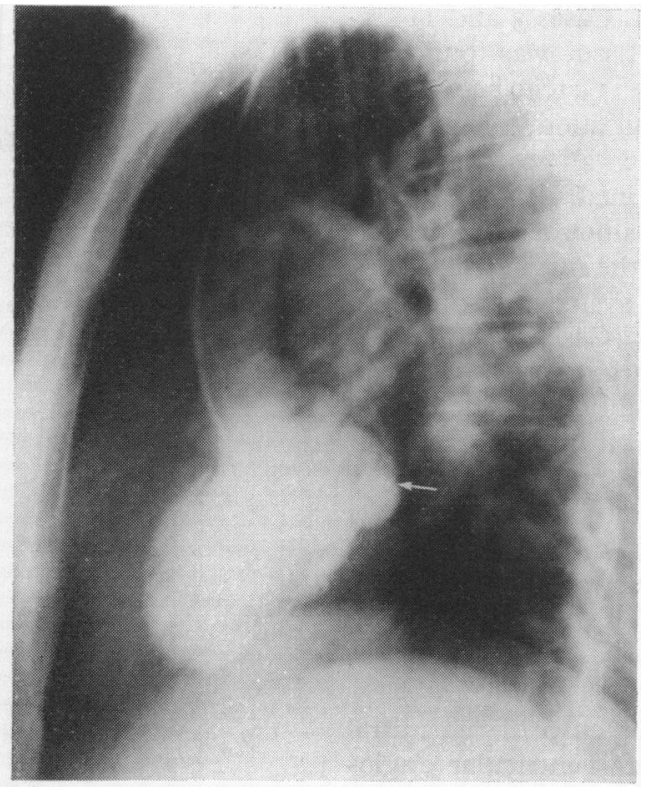

FIG. 4 Left ventricular angiogram, lateral view, Case 4. Arrow indicates large prolapse of posterior cusp of the mitral valve.

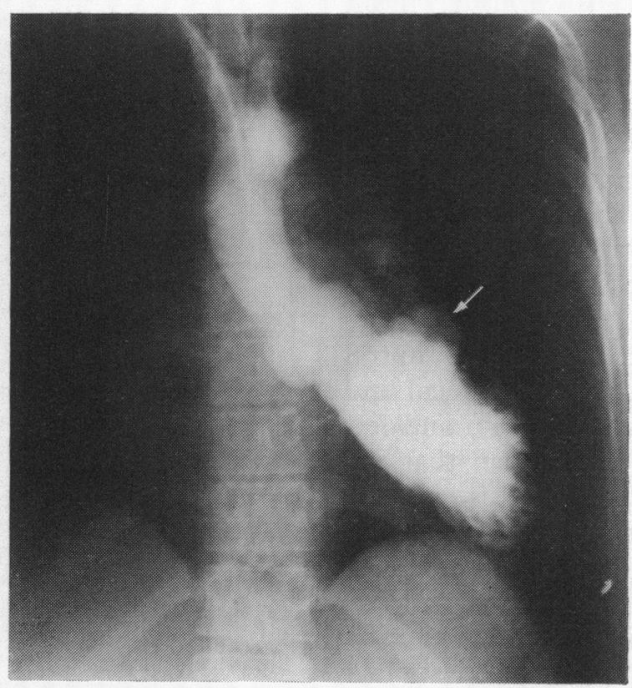

FIG. 5 Left ventricular angiogram, anteroposterior view, Case 4. Arrow indicates prolapse.

cannot be concluded that this abnormality was the consequence of rheumatic endocarditis. A familial incidence has been noted (Stannard et al., 1967; Hunt and Sloman, 1969). In two series (Hancock and Cohn, 1966; Barlow et al., 1968) two cases have been reported where prolapse was associated with atrial septal defects of secundum type. In our own experience and that of Barlow et al. (1968), prolapse has rarely been found with other congenital lesions such as persistent ductus arteriosus, ventricular septal defect, atrioventricular septal defect, and pulmonary stenosis. The familial tendency, association with congenital cardiac lesions, and its occurrence in children suggest that this abnormality of the mitral valve may be congenital. The coincidence of fossa ovalis atrial septal defects with prolapse could be a random association of two fairly common abnormalities. However, the authors have performed many left ventricular angiograms in patients with ventricular septal defects and have found the association of a ballooned posterior cusp to be extremely rare, suggesting that the association with fossa ovalis atrial septal defects may be more specific. There is little pathological information. A voluminous posterior cusp with elongated chordae has been found at necropsy in one case (Barlow et al., 1963), and reference to a localized expansion of the cusp has also been made (Hunt and Sloman, 1969). In the latter report the findings at operation in two patients with symptomatic mitral regurgitation were of ruptured chordae and large posterior mitral cusps, and others have reported similar findings (Marchand et al., 1966). In Marfan's syndrome the chordae have been found to be unduly lax (McKusick, I955; Raghib et al., 1965). These findings support the contention that the primary abnormality is chordal in origin leading to a progressive ballooning of the cusp (Barlow et al., 1968). The natural history of prolapse of the posterior cusp of the mitral valve is not known. It is possible that the severity of the mitral regurgitation may increase in time and cause significant symptoms. The risk of infective endocarditis in atrial septal defect of the fossa ovalis type is exceedingly small (Bedford, Papp, and Parkinson, 194I), but it may occur on the abnormal mitral valve in patients with atrioventricular defects. In patients with prolapse of the posterior cusp infective endocarditis has been found (Linhart and Taylor, 1966) and prophylactic antibiotic therapy at the time of septic hazard is indicated. When atrial septal defects of fossa ovalis type are associated with prolapse of the posterior cusp, especially where there are signs indicating mitral regurgitation, it is important to distinguish this combination from atrioventricular defects. The left ventricular angiographic features are distinct.

We would like to thank Drs. Wallace Brigden, Aubrey Leatham, and Edgar Sowton for permis- 
sion to report the findings in patients under their care. Mr. Charles Drew operated on Cases 4, 6, and Io, Mr. Keith Ross on Case 3, and Sir Thomas Holmes Sellors on Case Ir.

\section{References}

Barlow, J. B., and Bosman, C. K. (1966). Aneurysmal protrusion of the posterior leaflet of the mitral valve. American Heart fournal, 71, 166.

Barlow, J. B., Bosman, C. K., Pocock, W. A., and Marchand, P. (1968). Late systolic murmurs and non-ejection (' mid-late') systolic clicks. An analysis of 90 patients. British Heart fournal, 30, 203.

Barlow, J. B., Pocock, W. A., Marchand, P., and Denny, M. (1963). The significance of late systolic murmurs. American Heart fournal, 66, 443.

Baron, M. G., Wolf, B. S., Steinfeld, L., and Van Microp, L. H. S. (1964). Endocardial cushion defects. Specific diagnosis by angiocardiography. American fournal of Cardiology, 13, 162.

Bedford, D. E., Papp, C., and Parkinson, J. (194I). Atrial septal defect. British Heart fournal, 3, 37.

Cleland, W., Goodwin, J., McDonald, L., and Ross, D. (1969). Medical and Surgical Cardiology. Blackwell Scientific Publications, Oxford.

Criley, J. M., Lewis, K. B., Humphries, J. O'N., and Ross, R. S. (1966). Prolapse of the mitral valve: clinical and cine-angiocardiographic findings. British Heart fournal, $28,488$.

Hancock, E. W., and Cohn, K. (I966). The syndrome associated with midsystolic click and late systolic murmur. American fournal of Medicine, 41, 183.

Hunt, D., and Sloman, G. (I969). Prolapse of the posterior leaflet of the mitral valve occurring in eleven members of a family. American Heart fournal, 78, 149.
Linhart, J. W., and Taylor, W. J. (1966). The late apical systolic murmur. Clinical, hemodynamic and angiographic observations. American fournal of Cardiology, 18, 164.

McDonald, A., Harris, A., Jefferson, K., Marshall, J., and McDonald, L. (I970). Association of prolapse of posterior cusp of mitral valve and atrial septal defect. In Proceedings of the British Cardiac Society. British Heart fournal, 32, 554.

McKusick, V. A. (1955). The cardiovascular aspect of Marfan's syndrome: a heritable disorder of connective tissue. Circulation, II, 321.

Marchand, P., Barlow, J. B., du Plessis, L. A., and Webster, I. (1966). Mitral regurgitation with rupture of normal chordae tendineae. British Heart Fournal, 28, 746.

Raghib, G., Jue, K. L., Anderson, R. C., and Edwards, J. E. (I965). Marfan's syndrome with mitral insufficiency. American fournal of Cardiology, 16, 127.

Read, R. C., Thal, A. P., Wolf, P. L., and Wendt, V. E. (1964). Symptomatic valvular myxomatous degeneration: floppy valve syndrome. (Abstract.) Circulation, 30, Suppl. 3, 143.

Reid, J. V. O. (196I). Mid-systolic clicks. South African Medical fournal, 35, 353.

Segal, B. L., and Likoff, W. (1964). Late systolic murmur of mitral regurgitation. American Heart fournal, 67, 757.

Somerville, J., and Jefferson, K. (1968). Left ventricular angiocardiography in atrioventricular defects. British Heart fournal, 30, 446.

Stannard, M., Sloman, J. G., Hare, W. S. C., and Goble, A. J. (1967). Prolapse of the posterior leaflet of the mitral valve: A clinical familial, and cineangiographic study. British Medical fournal, 3, 7 I. 